Archives de sciences sociales des religions

172 | octobre-décembre

Bulletin Bibliographique

\title{
George Weigel, Le catholicisme évangélique
}

Paris, Desclée de Brouwer, 2015, 307 p.

\section{Vincent Petit}

\section{(2) OpenEdition}

\section{Journals}

Édition électronique

URL : http://journals.openedition.org/assr/27491

DOI : 10.4000/assr.27491

ISSN : $1777-5825$

Éditeur

Éditions de l'EHESS

Édition imprimée

Date de publication : 1 octobre 2015

Pagination : 390

ISBN : 978-2-7132-2515-4

ISSN : 0335-5985

Référence électronique

Vincent Petit, « George Weigel, Le catholicisme évangélique », Archives de sciences sociales des religions [En ligne], 172 | octobre-décembre, mis en ligne le 22 juin 2016, consulté le 23 septembre 2020. URL : http://journals.openedition.org/assr/27491 ; DOI : https://doi.org/10.4000/assr.27491

Ce document a été généré automatiquement le 23 septembre 2020.

(c) Archives de sciences sociales des religions 


\section{George Weigel, Le catholicisme évangélique}

Paris, Desclée de Brouwer, 2015, 307 p.

Vincent Petit

\section{RÉFÉRENCE}

George Weigel, Le catholicisme évangélique, Paris, Desclée de Brouwer, 2015, 307 p. 
1 Le catholicisme a-t-il encore un avenir ? Telle est la question qui barre la jaquette de l'édition française du livre de George Weigel, essayiste américain bien connu pour sa biographie de Jean-Paul II. Le sous-titre original sous lequel il est paru en 2013 correspond davantage à son contenu: «Evangelical Catholicism. Deep Reform in the 21st-Century Church ». En effet, George Weigel ne doute à aucun moment que le catholicisme ait un avenir : le ton est assuré, construit sur de solides convictions, et, pour tout dire, sur

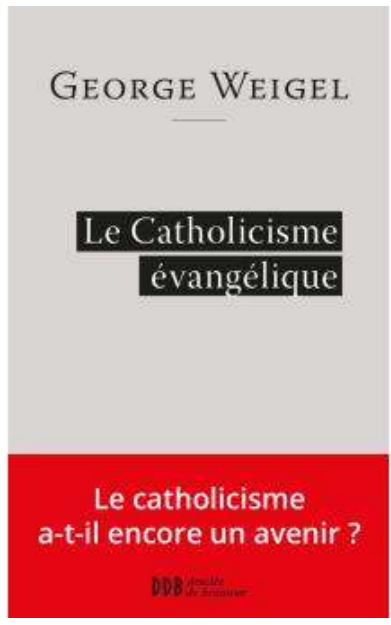
une forme de militantisme que montre l'emploi généralisé des verbes au futur. Point d'analyse géopolitique ou sociologique comparatiste, mais bel et bien un exercice d'apologétique comme les Européens n'en écrivent plus.

2 Apologétique ne signifie pas apologie: George Weigel n'est pas tendre envers les prêtres pédophiles, les évêques mondains, les défauts de communication du SaintSiège, et les laïcs inconséquents qui désirent recevoir les sacrements sans modifier leur mode de vie. Il organise son propos autour de deux parties : la vision d'un catholicisme évangélique et les réformes nécessaires qui permettront son plein épanouissement - ce qui entraîne parfois certaines redites. Précisons d'emblée que pour Weigel, le catholicisme évangélique, terme employé par le cardinal jésuite américain Avery Dulles dès 1991, n'est pas une copie des mouvements évangéliques protestants, mais qu'il constitue l'expression à venir du catholicisme romain. Toutefois les possibles ponts avec le protestantisme évangélique, seule autre confession mentionnée dans l'ouvrage, mériteraient sans doute plus de développements. S'il y a crise catholique, c'est une crise de passage entre l'ère de la Contre-Réforme et celle de ce catholicisme évangélique dont il observe l'émergence, au-delà du concile Vatican II et du pontificat de Jean-Paul II, à partir de l'élection de Léon XIII en 1878. Généalogie intraécclésiale discutable puisqu'elle intègre Pie XII, mais néglige les pontificats de Pie X et Pie XI.

3 Ce catholicisme évangélique qui se réclame de l'Esprit Saint (p.13) et appelle une nouvelle Pentecôte (p.30) est un catholicisme de la mission, de la conversion, de l'évangélisation, fondé sur l'amitié avec le Christ. Mais il est resté fondamentalement romain, avec son attachement à la liturgie, au magistère (Weigel se réfère constamment aux enseignements des papes et des conciles), à la papauté, à l'Église. Les réformes qu'il envisage concernent davantage une nouvelle gouvernance de l'Église, du diocèse (il insiste beaucoup sur le rôle des évêques) jusqu'à la Curie, avec un plus grand rôle accordé aux laïcs. Il renvoie dos-à-dos le traditionalisme et le progressisme (p. 28-29) et, par exemple, en ce qui concerne la liturgie, il se montre favorable à celle qui a été promulguée par Paul VI en introduisant toutefois certains changements, comme l'orientation commune du prêtre et des fidèles, suivant en cela les conceptions du cardinal Ratzinger dans L'Esprit de la liturgie, paru en 2000.

4 Selon lui, le catholicisme évangélique correspond à un style de vie " contre-culturel » (p. 51, 104, 174, 194, 226). Il ne doit donc pas craindre d'être en contradiction (p. 184) avec l'esprit dominant des sociétés occidentales, en réaffirmant par exemple le célibat 
ecclésiastique, les vertus du mariage chrétien, le refus de l'euthanasie et de l'avortement. Un chapitre traite même de la voix de l'Église dans les affaires publiques. L'intérêt essentiel du livre tient sans doute dans cette perception négative de la société, cette dénonciation de l'« impérialisme de la postmodernité laïque» (p. 196) accusée d'être soumise aux influences gnostiques (p. 61, ou « le déni radical de la nature donnée des choses " p. 242). Si la Contre-Réforme avait pu s'appuyer sur un substrat culturel qui lui avait facilité sa réception et son application, le catholicisme contemporain est partout confronté à une culture qui lui est majoritairement hostile ou indifférente, et n'a donc ni intérêt ni inclination à transiger : dans la droite ligne de l'école de la Radical orthodoxy - en particulier le livre de Catherine Pickstock, After Writing. On the Liturgical Consummation of Philosophy, 1998 (édition française: Après l'écrit. De l'achèvement liturgique de la philosophie, Paris, Ad Solem, 2013) - le catholicisme évangélique se nourrit d'un ressourcement théologique, et non d'une nécessaire adaptation pastorale à la modernité ou d'un quelconque accommodement raisonnable.

Historiquement le catholicisme évangélique tel que le décrit Weigel se rattache à une forme d'intransigeantisme, plus proche quoi qu'il en dise de Pie IX ou de Pie X que de Léon XIII, dont on oublie trop souvent au-delà de ses aspects réactionnaires, la vigueur spirituelle et le dynamisme missionnaire. L'intransigeantisme catholique se définit avec la dernière condamnation du Syllabus du pape Pie IX en 1864 : «Le Pontife romain peut et doit se réconcilier et transiger avec le progrès, le libéralisme et la civilisation moderne ", mais il est loin de se résumer à son seul attribut ecclésiologique puisqu'il a des prolongements dévotionnels, esthétiques, sociaux, politiques... On aurait tort de le confondre avec le traditionalisme ou avec l'intégrisme, de le concevoir uniquement comme une posture idéologique dirigée contre l'émergence des nations démocratiques et du capitalisme en voie de mondialisation. L'intransigeance doctrinale se veut avant tout un projet alternatif à la modernité libérale et marchande, ou tout du moins son correctif ; qu'en l'occurrence l'extension toujours plus grande de la seconde appelle une intransigeance, toute évangélique soit-elle, qui ne désarme pas. À rebours d'un constat unanimement admis, il faut s'interroger sur l'existence d'une dynamique particulière de la croyance religieuse, qui serait à l'inverse de nombre de pratiques sociales, proportionnelle au niveau d'exigence, d'intransigeance, de radicalité qu'elle impose. 